\title{
GRAMÁTICA TRADICIONAL E CATEGORIZAÇÃO LEXICAL
}

\author{
Paulo Juarez Rueda Strogenski \\ Mestre em Lingüística pela UFPR
}

\section{RESUMO}

Várias abordagens teóricas estudam o léxico a partir de sua classificação em classes ou categorias, o que, de maneira geral, vem-se mantendo mais ou menos constante desde a Grécia antiga. No entanto, como as línguas são vivas, produto de um constante "fazer" social, alguns usos que os falantes fazem das expressões lingüísticas acabam por desafiar as classificações estabelecidas, exigindo que as teorias sejam capazes de abarcar, também, esses novos usos. Um dos casos em que isso ocorre é o de itens lexicais que sofrem um processo de "nominalização" e passam a exibir características semelhantes às daqueles itens que são definidos como membros da categoria dos nomes. O presente artigo pretende tratar a forma como a Gramática Tradicional aborda esta questão.

De maneira geral, tradicionalmente, define-se sujeito como o termo da oração sobre o qual se diz algo. Segundo essa mesma definição, essa posição é normalmente ocupada por um substantivo. No entanto, há de se admitir que nem sempre as coisas são assim. Há momentos em que essa posição está ocupada por um outro elemento que não é um substantivo. E como se pode explicar tal fenômeno? Em princípio existem (ao menos) três maneiras: a) ou o elemento não ocupa a posição de sujeito, b) ou a definição está incorreta no que se refere à afirmação de que um substantivo possa ser o ocupante único dessa posição, c) ou deve-se aceitar o fato de que outros elementos do léxico que são definidos normalmente como elementos de outras classes também possam ser substantivos.

Em relação a (a), podemos tomar um exemplo como "correr faz bem à saúde" e parafraseá-lo como "corrida faz bem à saúde". Em ambas, correr e corrida desempenham o mesmo papel sintático, logo correr ocupa a posição de sujeito e (a) é falsa.

Aceitando-se que o elemento de fato ocupa a posição de sujeito talvez a terceira opção seja a mais acertada e então deveremos aceitar a idéia de que existe uma "mobilidade lexical" que permite que uma mesma palavra possa estar em mais de uma classe gramatical, assumindo os traços próprios de cada uma delas. Isso implicaria no fato de que (b) também é verdadeira.

Se partirmos desta idéia, então a noção de classe dos substantivos deverá sofrer uma mudança no sentido de poder abrigar esses outros itens lexicais que possam vir a "migrar" para ela, ou seja, talvez tenhamos que aceitar que exista uma função de substantivo e não uma classe, o que quer dizer que embora possam existir palavras que são sempre substantivos, a noção de função de substantivo é mais abrangente, pois é capaz de abarcar todos aqueles itens que estejam desempenhando essa função.

Voltando à definição de sujeito, se aceitarmos que a posição de sujeito de uma oração só possa se preenchida por um nome (ou substantivo), então é preciso aceitar-se o fato de que a 
categorização tradicional não pode ser levada ao pé da letra (tendo-se em vista inúmeros exemplos que contradizem essa afirmação), o que quer dizer que as palavras não podem ser separadas em categorias por elas próprias, mas sim pelos papéis, sintático e semântico, que elas são capazes de desempenhar em um ambiente de uso lingüístico. Isso implica em assumirmos que o uso que os falantes fazem de umalíngua extrapola em muito as categorizações estritas que as teorias às vezes fazem. Nos exemplos abaixo, é possível perceber, mesmo que intuitivamente, que a palavra brincar desempenha papéis sintáticos diferentes em cada ambiente.

(1) a. João foi brincar.

b. Brincar é bom.

c. João gosta de brincar.

Em (1a), brincar faz parte da locução verbal "foi brincar", que desempenha o papel sintático de predicado verbal de João. O mesmo não ocorre nos exemplos (1b) e (1c), nos quais brincar desempenha respectivamente as funções de sujeito em (1b) e de objeto em (1c).

Em (1b) a estrutura frasal permite substituições do tipo: correr é bom, caminhar é bom, sorvete é bom, etc., de forma que é possível que outras palavras também ocupem a função que brincar ocupa. O exemplo (1c) é semelhante ao anterior no sentido de que também permite substituições do mesmo tipo. Pode-se dizer "João gosta de brincar", da mesma forma que se pode dizer que "João gosta de sorvete", ou seja, brincar e sorvete são capazes de desempenhar a mesma função num mesmo ambiente, apresentando significados próprios, naturalmente, mas que, num primeiro momento, parecem fazer parte de um mesmo tipo.

Percebe-se, nos dois casos, que ambas as palavras são nomes de coisas, ou seja, ambas as palavras fazem parte de um mesmo grupo de significação, porque João gosta de duas coisas (neste caso): de sorvete e de brincar. Logo, a palavra brincar, no contexto, acaba por desempenhar não só a mesma função sintática, mas também o papel de significar o nome de uma coisa de que João gosta.

Pode-se, naturalmente, argumentar que, apesar de as duas palavras significarem coisas das quais João gosta, elas definem objetos de esferas de significação diferentes, já que "sorvete" refere-se a um objeto palpável e "brincar" a uma ação. No entanto, há de se admitir que apesar das diferenças, existem também semelhanças, porque alguém pode gostar igualmente de coisas diferentes em sua essência, mas que fazem parte de um mesmo conjunto: o conjunto das coisas de que alguém gosta. $E$ esse conjunto seria uma limitação que o indivíduo, a partir de sua experiência de vida e de sua individualidade, faz. Nos exemplos acima, existem duas afirmações sobre os gostos de João, sobre dois dos objetos da realidade que fazem parte do conjunto de todas as coisas que, por uma razão ou outra, João aprecia. Conjunto no qual pode estar um número infinito de objetos animados (cachorro, gato, mãe, pai...), inanimados (bola, carrinho, pirulito, sobremesa...) e também ações (dormir, dançar, comer, sorrir...). 
O que se pode assumir a respeito dos objetos citados acima é que eles formam subconjuntos de tipos diferentes, com traços próprios a cada um deles. Até mesmo o fato de que eles estão ligados à idéia de "gostar" já faz com que a relação de cada um deles com o conjunto seja diferenciada, pois normalmente as pessoas "gostam" de maneiras diferentes, dependendo do objeto em questão. Geralmente se gosta mais da mãe do que do gato, ou aprecia-se mais a sobremesa do que o pirulito, mas isso resultaria em apenas mais um traço individual para se diferenciar objetos pertencentes a um mesmo subconjunto do que, propriamente, num aspecto relevante para a análise de todos os objetos como membros, ou não, de um mesmo conjunto.

A mesma noção de conjunto pode ser aplicada também às categorias gramaticais tradicionais. A categoria dos substantivos é, em essência, o conjunto de todas as palavras que possuam traços em comum tais que permitam a sua inclusão no conjunto dos substantivos (ou dos nomes). $O$ mesmo deve acontecer com todas as outras categorias gramaticais como os adjetivos, os advérbios, os verbos, etc. O problema é que nem sempre isso é tão facilmente definido, como nos exemplos abaixo:

(2) a. O carro é vermelho.

b. Vermelho é uma bonita cor.

c. Bonita é uma característica que pode ser aplicada a seres do gênero feminino.

(3) a. João vai caminhar todas as manhãs.

b. Caminhar é bom para a saúde.

(4) a. O desenho foi colorido.

b. O mundo é colorido.

c. Colorido é mais bonito.

Em (2a), vermelho desempenha o papel predicativo de dizer algo sobre o carro. Neste caso, é claramente um adjetivo. Já em (2b) o papel que a palavra desempenha é o de sujeito de "é uma bonita cor". Aqui, a palavra já não pode mais ser enquadrada como sendo um adjetivo. $O$ mesmo se aplica ao adjetivo bonita em (2b) e (2c).

Nos exemplos do grupo (3), a mesma coisa acontece com o infinitivo do verbo caminhar, o qual em (3a) faz parte do SV "vai caminhar todas as manhãs" e, em (3b), ao contrário, é sujeito.

Com o particípio do verbo "colorir", nos exemplos do grupo 3, também ocorre o mesmo fenômeno. Em (4a), colorido é verbo no particípio e parte do predicado "foi colorido", referindose ao sujeito "o desenho". Em (4b), é expressão predicativa de "o mundo" e pode ser classificado como um adjetivo. Finalmente, em (4c), é parte do sujeito da oração e, de qualquer maneira, da mesma forma que acontece com caminhar, em (3b), não pode mais ser classificado 
como um verbo.

Além dos casos acima, ainda pode-se perceber um fenômeno semelhante nos exemplos abaixo:

(5) Quem telefonou vem para o jantar?

Em (5), "quem telefonou" está desempenhando a função de "sujeito pronominal", substituindo um nome que é representado por um pronome (que aliás já tem esta função de substituir o nome).

(6) Que João viaje desagrada a Maria.

A construção (6) apresenta uma conjunção integrante introduzindo "que João viaje", a qual também é sujeito. O que acontece em (5) e (6) parece, em princípio, assemelhar-se ao que acontece em(2), (3) e (4): um elemento que não era originalmente um nome passa a desempenhar o seu papel específico, ou seja, passa a apresentar características típicas de um nome.

O fenômeno que ocorre nos três casos parece um tipo de flutuação sistêmica, uma capacidade que as palavras têm de mudar de categoria morfológica quando mudam sua função sintática. Isso quer dizer que, na verdade, um verbo no infinitivo é apenas verbo quando tomado isoladamente, fora do contexto de uma sentença. A partir do momento em que ele estiver inserido num contexto, somente seu papel sintático poderá determinar a que categoria morfológica estará inserido no momento.

Nos exemplos citados até aqui, apareceram casos de palavras que deixaram suas categorias de base para desempenharem as funções de sujeito e objeto que, tradicionalmente, deveriam ser desempenhadas por nomes (ou substantivos). O que se pretende no presente trabalho é procurar demonstrar que as categorias tradicionais não são tão estanques como se pretende, mas sim que permitem uma certa mobilidade para alguns tipos de palavras, mais precisamente quando palavras de outras categorias gramaticais passam a ter um comportamento típico daquele dos membros da categoria dos nomes.

Esse processo de "migração" para a categoria dos nomes é comumente chamado de NOMINALIZAÇÃO, o qual pode ser percebido em momentos em que palavras (como verbos, por exemplo) passam a exibir um comportamento sintático/semântico semelhante àquele próprio de um nome. Esse processo também pode ser exemplificado pelo fato de que a maioria das palavras do português podem ser nominalizadas com o uso de artigos:

(7) a. O cavalo é belo.

b. O belo é uma característica da arte.

ou com o uso de sufixos: 
(8) a. João andou rápido.

b. A rapidez é uma necessidade.

ou ainda da metalinguagem:

(9) a. Rapidamente é um advérbio.

b. Mas é uma conjunção.

É preciso também que se diga que esse processo não é uma exclusividade do português. Em inglês (e provavelmente em outras línguas) também existem inúmeros exemplos de casos de nominalização:

(10) a. The sky is blue.

b. Blue is a nice colour.

c. Children run out the school.

d. Running is a good exercise.

e. John's running is beautiful.

A Gramática Tradicional trata de alguns casos nos quais ocorre a nominalização (ou substantivação), embora sem se preocupar com o processo, como ocasiões em que algum elemento substitui o nome, desempenhando o seu papel, como é o caso dos pronomes substantivos, das orações subordinadas substantivas e também de qualquer palavra que possa ser determinada, como os adjetivos e os advérbios. Rocha Lima afirma:

"Qualquer palavra, expressão ou oração pode ser substantivada." (p. 262)

e apresenta o seguinte exemplo de Olavo Bilac:

"O não que desengana, o nunca que alucina..." (idem)

Esse pensamento que vigora hoje em dia nas gramáticas que seguem essa linha é insuficiente para explicar fatos como os apontados anteriormente. Vamos ver alguns exemplos retirados de trabalhos escolares de frases que foram produzidas por adolescentes da faixa etária de 16 a 18 anos, os quais, em princípio, representam uma camada da população que teve acesso à educação, mas que, ao mesmo tempo, ainda conserva uma certa espontaneidade:

(1) a. Azul é uma cor alegre.

b. Azul é uma cor calma.

c. Correr é um esporte magnífico. 


\section{d. Correr faz bem à saúde.}

e. Amar é uma questão de escolha.

Nas sentenças acima encontramos casos de palavras que não estão determinadas por artigo, possessivo, outro elemento determinante, mas que nestes contextos estão desempenhando a função de sujeito das sentenças e são claramente nomes de alguma coisa (uma cor ou uma ação). Se elas são nomes de alguma coisa, então, nestes contextos elas fazem parte da classe dos substantivos.

Por outro lado, se elas não forem consideradas nomes, seria necessário mudar a definição de sujeito para que esta pudesse abarcar os casos apontados. Daí teríamos que aceitar uma definição do tipo: "sujeito é qualquer item lexical que represente o nome de alguma coisa sobre o qual se diz algo", a qual parece carecer de qualquer rigor formal.

A explicação que os gramáticos dariam para esses fatos seria alguma coisa como: em (1a) e (1b) nós temos casos de derivação imprópria e nos demais exemplos tratam-se de orações substantivas reduzidas de infinitivo. Mais tarde voltaremos a essas definições.

Um aspecto interessante que pode ser notado ao se examinar os trabalhos dos gramáticos é o fato de que a elaboração da NGB (Nomenclatura Gramatical Brasileira) representou um retrocesso no que se refere à liberdade que os teóricos tinham (e têm) para pensar e até especular sobre os fatos da língua portuguesa. Antes da NGB havia um sério problema de falta de uniformização de discursos, já que cada gramático tinha liberdade para criar termos que fossem necessários para explicar os fenômenos que eles observavam. Isso causava problemas em diversos níveis, desde o nível da publicação de gramáticas até problemas escolares, pois cada professor também tinha liberdade para seguir um ou outro autor ou até mesmo criar seus próprios nomes para os fatos da língua.

Só para ilustrar: Gladstone Chaves de Melo aponta os seguintes exemplos que eram encontrados antes da NGB: "as dicotomias sujeito 'gramatical' e 'lógico', 'complexo' e 'incomplexo' (...) a classificação dos verbos, complicadíssima, tendo em vista o regime, a conjugação, a metafonia, etc., o que gerava quantidade de nomes como transitivo relativo, biobjetivo, transobjetivo, regular, irregular gráfico, semi-irregular, defectivo, unipessoal, redundante, e outros." (p.301)

Se por um lado havia esse problema de falta de uniformidade, por outro, os gramáticos tinham uma certa liberdade para pensar e levantar hipóteses sobre a língua, o que, de certa forma, tornou-se marginal após a NGB. Marginal não no sentido de ser menos científico (muito ao contrário), mas no sentido de ir contra um pensamento institucionalizado, já que, a partir de sua promulgação, a NGB passou a ser o instrumento através do qual a língua portuguesa passou a ser ensinada nas escolas, cobrada em concursos, etc.

Ao buscarmos trabalhos de gramáticos que ainda estavam liberados da NGB, é possível 
encontrar reflexões bastante interessantes a respeito dos fatos lingüísticos como o trecho que colocamos abaixo, retirado de Said Ali, da sua Gramática histórica da língua portuguesa, que trata-se na verdade de uma edição revisada de Lexeologia e formação de palavras e sintaxe do português histórico, de 1921 (alguns trechos foram sublinhados por mim porque parecem particularmente interessantes):

"As línguas enriquecem o seu vocabulário, não somente combinando palavras entre si ou ajuntando-lhes prefixos e sufixos, mas ainda dando a certos vocábulos sentido novo, fazendo-os servir em categoria diferente. Ser, jantar, dever, poder tanto são infinitivos como substantivos. $O$ frio, o belo, o sublime aplicam-se a noções abstratas; o cego, o louco, o rico, o avarento referemse a pessoas, funcionando pois o adjetivo como substantivo. Tais fatos se observam na linguagem, quer estudada sincronicamente quer examinada diacronicamente. Lente, ribeiro, receita, estado, oriente, hoje usados só como substantivos, procedem de antigos adjetivos e particípios.

No entender de alguns gramáticos, faz parte da derivação o estudo deste enriquecimento do vocabulário sem auxílio de elementos formativos, e dão-lhe o nome de derivação imprópria por serprocesso notoriamente dissemelhante do processo comum. Não adotaremos aqui esse parecer. A mudança de sentido e de função que sofrem as palavras, examina-se em outras partes da gramática, e, a dedicar-se uma parte especial a tão interessante assunto, deverá denominar-se semântica e não derivação." (p. 230, 231)

Como se pode observar pelas partes sublinhadas, já em 1921, Said Ali reconhecia que existe um mecanismo dentro da língua que permite o enriquecimento do vocabulário através de um processo de mudança de classe gramatical. Além disso, outra observação digna de nota que ele faz é a de que um assunto tão interessante não deve ser tratado dentro do âmbito da derivação, mas no da semântica, demonstrando assim que, na sua visão, esse processo ultrapassa o artifício quase "mecânico" da sufixação.

Por outro lado temos os autores que seguem a NGB, como é o caso de Celso Cunha. Segundo ele, os casos em que ocorre a nominalização seriam aqueles que ele chama de casos de "derivação", quando uma palavra é modificada por sufixo, como por exemplo:

1. correr/ corrida; fugir/ fugitivo; belo/ beleza; rápido/ rapidez; pobre/

pobreza; etc.,

nos quais nós temos infinitivos e adjetivos que passaram a ser nomes através da colocação de sufixos; e de "derivação imprópria", que seria o caso já citado anteriormente de se antepor um artigo ou um determinante a qualquer vocábulo da língua, como:

(3) a. Meu não é definitivo.

b. O azul é uma bonita cor. 


\section{c. O belo é uma qualidade da arte.}

É claro que essa explicação é insuficiente para se explicar a ocorrência dos exemplos (1a) e (1b), nos quais a palavra azul é usada como substantivo e não está determinada nem por artigo e nem por qualquer possessivo, o que significa que esse processo é alguma coisa a mais do que simplesmente antepor artigos ou determinantes aos vocábulos.

Em relação aos infinitivos que possam ocupar a posição de sujeito em uma sentença, ele vai chamar isso de oração reduzida de infinitivo. Isso implica em aceitar-se que correrem "Correr é bom" não se trata apenas de um infinitivo, mas de uma oração reduzida de infinitivo, a qual, acredito eu, deveria talvez corresponder ao nome da propriedade "correr" ou "ato de correr", o que também implicaria numa relação semântica entre o vocábulo e a idéia que ele veicularia.

Uma outra possibilidade é a de se pensar que se de fato essa derivação é "imprópria", ela seja uma falsa derivação. Se ela for uma falsa derivação então é outra coisa que não uma derivação. Mas o fenômeno existe, as construções são possíveis e acontecem, logo precisa ser explicado por outra hipótese diferente da defendida pela "derivação imprópria".

Vamos propor duas possibilidades de análise: a primeira baseia-se na idéia de que existe derivação. Se assumirmos que existe derivação então deveremos aceitar que algumas palavras do léxico possam, digamos, "estar a deriva" no mar do léxico. Isso quer dizer que essas palavras estariam sujeitas às marés e às diversas correntes. Essa analogia com o mar me parece interessante porque quando um barco está a deriva no mar ele está sujeito a determinadas correntes que podem levá-lo para uma ou outra direção, dependendo do ponto do mar em que esse barco esteja.

Voltando à questão da derivação, uma palavra que estivesse à deriva estaria em algum ponto em algum ponto do léxico, que seria definido pelas marcas de possibilidade de inserção lexical que ela possuísse. Por exemplo, a palavra azul teria marcas de inserção como substantivo e como adjetivo e essas marcas a colocariam à deriva num ponto do léxico em que estaria sujeita a ser influenciada por uma corrente que a levasse para uma classe ou outra, dependendo do uso que fosse feito dela.

A inserção seria feita sem marcas de sufixo, o que, já a primeira vista contradiz a idéia de derivação "própria", a qual prediz que a derivação será feita através de sufixo. Isso quer dizer que se assumirmos essa hipótese, ela não caberia nem na definição de derivação nem na de derivação "imprópria".

A segunda possibilidade é admitirmos o seguinte: no caso da derivação "própria" o que acontece é que nós podemos pegar, por exemplo, um adjetivo como verde e, através da colocação de um sufixo, derivar o substantivo verdura. Verde e verdura serão então duas palavras diferentes, pertencentes a duas classes diferentes. Mas como foi visto pelos exemplos em (1), nós podemos também construir uma sentença como: Verde é uma cor relaxante, na qual verde também é um substantivo. Por analogia com o que acontece com verde e verdura, 
podemos conceber que aqui aconteceu o mesmo: o substantivo verde foi derivado do adjetivo verde, só que sem o uso do sufixo. Isso vai acarretar em aceitarmos também que verde substantivo

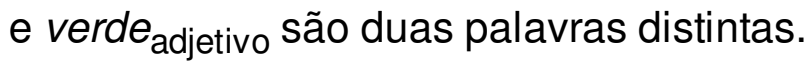

A primeira proposta, apesar de parecer possível em outra teoria, não poderia ser aceita dentro do âmbito da gramática tradicional porque um dos preceitos desta é o de que as palavras pertencem a classes bem definidas e compartilham das características inerentes a essas classes.

Já a segunda parece ser mais aceitável dentro da própria gramática tradicional porque esta já prevê a possibilidade de homonímia. No entanto, ela traria como conseqüência a ampliação da base lexical porque não seria um caso isolado (o da palavra verde), mas um fenômeno que atingiria um grande número de palavras de várias classes gramaticais. Por exemplo, nós poderíamos ter:

(4) a. correndo gerúndio João está sempre correndo.

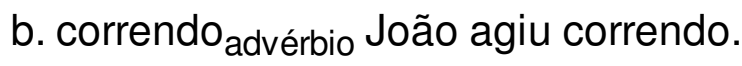

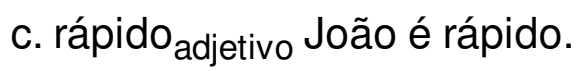

d. rápido advérbio João agiu rápido.

e. amado $_{\text {particípio }}$ João não se arrepende de tê-la amado.

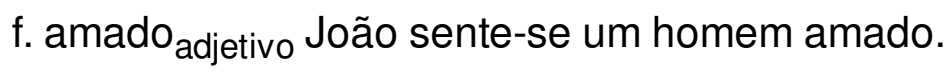

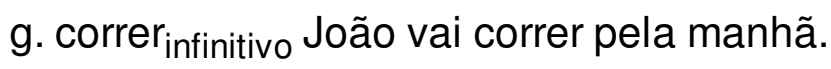

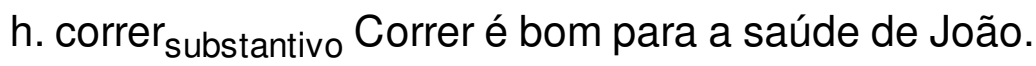

As duas hipóteses, de certa maneira, estão de acordo com as palavras de Said Ali citadas anteriormente, porque ambas explicariam o fato de que algumas palavras às vezes são infinitivos e outras vezes são substantivos.

De qualquer forma, seria inconveniente para a gramática tradicional pós-NGB porque, como já foi dito, grande parte dela é fundamentada na noção de classes bem definidas, nas quais as palavras possam ser inseridas sem passar pelo crivo de uma análise contextual. Talvez isso fosse possível através da modificação da definição de classe e da própria eliminação das classes tradicionais e adoção de outras classes. Por exemplo, Gladstone Chaves de Melo propõe uma divisão em cinco classes: nome, determinante (artigo, possessivos, indefinidos, adjetivos, advérbios), pronome (quando substitui o nome), verbo e conectivo (conjunções, preposições, pronomes relativos). Não vamos aqui discutir se essa classificação é melhor ou pior do que a tradicional, mas apenas admitir que existem maneiras diferentes de se tratar o 
léxico.

Vamos ver mais afirmações que contradizem a posição de Celso Cunha e da NGB. Torres (1965) concorda com a posição de Said Ali a respeito da chamada "derivação imprópria":

"A chamada derivação imprópria, que consiste na formação de vocábulos pela mudança de categoria gramatical, pertence mais ao domínio da semântica, que estuda a significação das palavras, do que propriamente à morfologia." (p.42)

Ao falar das formas nominais dos verbos ele diz:

"O infinitivo enuncia um fato de modo vago ou indefinido e corresponde, geralmente, a um substantivo." (p.91)

Rocha Lima (1983), já citado anteriormente, apesar de ter sido um dos elaboradores da NGB, juntamente com Celso Cunha, Antenor Nascentes e outros professores do Colégio D. Pedro II, ainda consegue escapar um pouco das normas instituídas e perceber que existe uma certa liberdade lexical no que se refere às classes gramaticais. Em sua gramática, encontramos as seguintes definições para verbo:

"O infinitivo é antes de tudo um substantivo: como este pode ser sujeito ou complemento de um verbo, e, até, vir precedido de artigo.

O particípio tem valor e forma de adjetivo: modifica substantivos com os quais concorda em gênero e número; apresenta o feminino em - a, e o plural em - s.

O gerúndio equipara-se ao advérbio, pelas várias circunstâncias de lugar, tempo, modo, condição, etc., que exprime." (p.107)

Outro autor que faz observações muito interessantes a respeito da formação e uso do léxico é Gladstone Chaves de Melo. Em seu livro, no capítulo chamado de "A constituição do vocabulário", ele afirma que, além das palavras herdadas e das importadas de outros idiomas, existem três processos de formação de palavras: derivação, mudança de classe e composição. Sobre o segundo processo, o qual nos interessa mais diretamente, ele diz que "Por mudança de classe, como o nome indica, se deve entender a passagem de palavras de uma a outra classe gramatical, onde adquirem outra significação ou diverso matiz semântico" (P.219).

No capítulo sobre análise sintática, quase em resposta à afirmação de Celso Cunha, colocada acima, a respeito dos infinitivos e particípios, ele afirma que é "Inútil quase sempre estar a falar em orações reduzidas, já que o infinitivo, o gerúndio e o particípio são nada mais que substantivos ou adjetivos verbais que exercem nas frases função de sujeito, de objeto, de complemento, de adjunto adnominal, de adjunto adverbial..." (p.249). No final do livro, quando comenta sobre a nomenclatura gramatical, ele faz outra observação muito interessante sobre as incoerências da NGB no que se refere às orações reduzidas: "Também não é admissível que se fale sistematicamente em orações reduzidas todas as vezes que se tem um infinitivo, um particípio ou um gerúndio a exercer a função $X$ ou $Y$ na oração $A$ ou $B$. Como seria possível 
harmonizar isso com a doutrina "cientificamente exata" se um infinitivo, gerúndio e particípio são "formas nominais do verbo"? Como seria possível harmonizar isso com o princípio de que se deve analisar a expressão tal qual se apresenta e nunca uma eqüissignificante, que é sempre sintaticamente outra?" (p.306). O que de certa forma vem a corroborar muitos dos exemplos colocados na parte introdutória deste trabalho, os quais apesar de estarem nos exemplos dados desempenhando a função de nome, deveriam ser tratados, segundo a NGB, como orações reduzidas, o que nos parece acima de tudo uma tentativa de buscar dentro da ideologia da gramática tradicional uma reposta que não fira os seus dogmas.

\section{REFERÊNCIAS BIBLIOGRÁFICAS}

CUNHA, C. Gramática do português contemporâneo. $8^{\underline{a}}$ ed. Rio de Janeiro: PadrãoLivraria Editora, 1980.

MELO, G. C. Iniciação à filologia e à lingüística portuguesa. $5^{\mathrm{a}}$ ed. Rio de Janeiro: Livraria Acadêmica, 1975.

ROCHA LIMA, C. H. Gramática normativa da língua portuguesa. 23를 ed. Rio de janeiro: José Olympio, 1983.

SAID ALI, M. Gramática histórica da língua portuguesa. $7^{a}$ ed. Aumentada e melhorada de Lexeologia e formação de palavras do português histórico. Rio de Janeiro: Livraria Acadêmica, 1971.

TORRES, A. A. Moderna gramática expositiva da língua portuguesa. $17^{a}$ ed. revista e melhorada. São Paulo: Editora Fundo de Cultura, 1965. 